\title{
Organic and mineral fertilization of maize affecting prevalence of fusarium diseases (Fusarium spp.) and European corn borer (Ostrinia nubilalis Hbn.)
}

\author{
Nawożenie organiczne i mineralne kukurydzy \\ kształtujące występowanie chorób fuzaryjnych (Fusarium spp.) \\ oraz omacnicy prosowianki (Ostrinia nubilalis $\mathrm{Hbn}$.)
}

Piotr Szulc

\section{Summary}

The aim of the study was to assess the consequent influence of one-time used full dose of manure after 10 years of maize cultivation in monoculture and diverse mineral fertilization NPK on health of maize plants. No significant influence of application of a full dose of manure on 10-year maize cultivation in monoculture on plant infestation with fungi of the genus Fusarium spp. and damages caused by Ostrinia nubilalis was found in subsequent years of the cultivation. Application of PK before sowing and $\mathrm{N}$ in the 5-6 leaf stage (BBCH 15-16) decreased plant health in comparison with objects where NPK was used before maize sowing. Plant infestation with fungi of the genus Fusarium spp. and damages caused by $O$. nubilalis increased in the subsequent years of maize cultivation in monoculture. A high positive coefficient of correlation between prevalence of European corn borer and maize plant infestation with fusarium diseases was demonstrated.

Key words: maize, monoculture, manure, fertilization NPK, maize health

\section{Streszczenie}

Celem badań było określenie następczego wpływu zastosowanej jednorazowo pełnej dawki obornika po 10 latach uprawy kukurydzy w monokulturze oraz zróżnicowanego nawożenia mineralnego NPK na zdrowotność roślin kukurydzy. Nie wykazano istotnego wpływu przerwania nawożenia pełną dawką obornika 10-letniej uprawy kukurydzy w monokulturze na wielkość porażenia roślin w kolejnych latach uprawy przez grzyby rodzaju Fusarium spp. oraz uszkodzenia powodowane przez Ostrinia nubilalis. Stosowanie PK przed siewem oraz N w fazie 5-6 liści (BBCH 15-16) zmniejszało zdrowotność roślin w porównaniu do obiektów, na których NPK stosowano przed siewem kukurydzy. Porażenie roślin przez grzyby rodzaju Fusarium spp. oraz uszkodzenia powodowane przez $O$. nubilalis zwiększały się w kolejnych latach uprawy kukurydzy w monokulturze. Wykazano wysoki, dodatni współczynnik korelacji pomiędzy występowaniem omacnicy prosowianki a porażeniem roślin kukurydzy przez choroby fuzaryjne.

Słowa kluczowe: kukurydza, monokultura, obornik, nawożenie NPK, zdrowotność kukurydzy

\footnotetext{
Uniwersytet Przyrodniczy w Poznaniu

Katedra Agronomii

Dojazd 11, 60-632 Poznań

pszulc@up.poznan.pl
} 


\section{Wstęp / Introduction}

Kukurydza (Zea mays L.) w wyniku intensywnej pracy hodowlanej została dobrze przystosowana do warunków klimatycznych Polski. Wprowadzane systematycznie do uprawy nowe odmiany, bardziej przystosowane do naszych warunków przyczyniają się ciagłego wzrostu powierzchni jej uprawy. Według Kusia i wsp. (1993) w okresie ostatnich lat, na skutek oddziaływania czynników ekonomicznych i organizacyjnych nastąpił znaczny wzrost udziału zbóż w strukturze zasiewów. Spowodowało to ograniczenie dostępności odpowiednich stanowisk dla roślin zbożowych, w tym również dla kukurydzy, wymuszając uprawę po sobie. Taka uprawa niesie ze sobą korzystne oraz niekorzystne oddziaływanie na roślinę oraz środowisko naturalne (Howard 1996; Tabaglio i Gavazzi 2009). Kukurydza jest gatunkiem mało wymagającym, odnośnie rośliny przedplonowej, tolerując uprawę po sobie, czyli uprawę w monokulturze (Menzel i Dubas 2003). Niemniej jednak wyniki badań informują o tym, że kukurydza uprawiana $\mathrm{w}$ płodozmianie plonuje wyżej w porównaniu do uprawy w monokulturze (Wesołowski i Woźniak 1998; Dubas i wsp. 2012). Jako sposoby ograniczające skutki niewłaściwego następstwa zbóż wymienia się zwiększenie nawożenia mineralnego, chemiczną ochronę roślin, intensywną uprawę roli, uprawę międzyplonów na zielony nawóz oraz zmianowanie odmian (Kotwica 2004).

Problemy z chemicznym zwalczaniem agrofagów oraz malejąca ilość zarejestrowanych środków ochrony roślin zdaniem Beresia i Pruszyńskiego (2008) są aktualnie powodem poszukiwania nowych rozwiązań ograniczania ich liczebności. Jedna $\mathrm{z}$ metod wykorzystywanych w integrowanej ochronie kukurydzy jest prawidłowe żywienie roślin. Decyduje ono nie tylko o wielkości plonu, ale zwiększa ponadto odporność roślin na porażenie przez choroby i żerowanie szkodników. Potwierdza to również Krauss (2001), według którego stopień presji pasożyta na roślinę uprawną jest wypadkową stanu jej odżywienia.

Celem przeprowadzonego badania polowego było określenie następczego wpływu zastosowanej jednorazowo pełnej dawki obornika po 10 latach uprawy kukurydzy w monokulturze oraz zróżnicowanego nawożenia mineralnego NPK na zdrowotność roślin kukurydzy oraz szkodliwość omacnicy prosowianki.

\section{Materiały i metody / Materials and methods}

Doświadczenie polowe wykonano w Katedrze Agronomii Uniwersytetu Przyrodniczego w Poznaniu, na polach Zakładu Dydaktyczno-Doświadczalnego w Swadzimiu, w latach 2008-2011. W roku 2007, tj. po 10 latach uprawy kukurydzy w monokulturze zastosowano jednorazowo jesienią 30 ton obornika, natomiast nawożenie mineralne zróżnicowano na NPK przed siewem i PK przed siewem, natomiast $\mathrm{N}$ aplikowano $\mathrm{w}$ fazie 5-6 liści (BBCH 15-16). Nawożenie mineralne stosowano w następującej ilości: $90 \mathrm{~kg} \mathrm{~N} /$ ha (mocznik), $80 \mathrm{~kg} \mathrm{P}_{2} \mathrm{O}_{5} /$ ha (superfosfat potrójny granulowany) i $120 \mathrm{~kg} \mathrm{~K} \mathrm{~K}_{2} \mathrm{O} /$ ha (sól potasowa $60 \%$ ). Obornik bydlęcy użyty $\mathrm{w}$ doświadczeniu polowym za- wierał: 4,7 g azotu/kg s.m.; 4,9 g fosforu/kg s.m.; 7,8 g potasu/kg s.m. Kukurydza uprawiana była po głębokiej orce jesiennej wykonanej standardowo na głębokość $30 \mathrm{~cm}$. Wielkość poletek wynosiła $34,72 \mathrm{~m}^{2}$ (szerokość: $5,6 \mathrm{~m}$, długość: $6,2 \mathrm{~m}$ ), do zbioru $26,04 \mathrm{~m}^{2}$ po odrzuceniu skrajnych rzędów stanowiących tzw. obsiewy.

W przeprowadzonych badaniach polowych notowano wystapienie chorób fuzaryjnych (Fusarium spp.) i omacnicy prosowianki (Ostrinia nubilalis Hbn.). Analizie poddano wszystkie rośliny będące na poletku tzn. 220 sztuk $\left(8,44 \mathrm{szt} . / \mathrm{m}^{2}\right)$. Notowano wyłącznie liczbę roślin, które zostały zaatakowane przez szkodnika lub porażone przez patogena, a wynik wyrażono w procentach. Uszkodzenie roślin kukurydzy przez omacnicę prosowiankę określono w fazie dojrzałości woskowej ziarniaków (BBCH 85), natomiast występowanie chorób fuzaryjnych oznaczano przed zbiorem kukurydzy.

Wyniki poddano statystycznej analizie zmienności dla doświadczeń czynnikowych ortogonalnych, następnie wykonano syntezę dla doświadczeń wieloletnich. Istotność różnic oszacowano na poziomie $\alpha=0,05$ za pomocą testu t-Studenta. Uzyskane wyniki w procentach przeliczono na stopnie kątowe Blissa. Do obróbki statystycznej uzyskanych danych wykorzystano program STATPAKU.

Warunki termiczne i wilgotnościowe panujące w sezonach wegetacyjnych kukurydzy przedstawiono na rysunku 1.

\section{Wyniki i dyskusja / Results and discussion}

Porażenie roślin kukurydzy przez grzyby rodzaju Fusarium spp. determinowane było zmiennymi warunkami pogodowymi w latach, długością uprawy w monokulturze oraz czynnikami doświadczenia (tab. 1). Średnio dla lat, niezależnie od badanych czynników najmniejszą wielkość porażenia odnotowano $\mathrm{w}$ roku $2008(0,75 \%)$, natomiast największą w roku $2011(18,49 \%)$, tzn. w trzecim roku po zastosowanym oborniku. Pozostałości po zbiorze kukurydzy (resztki pożniwne) są najważniejszym źródłem dla zarodników grzybów pleśniowych. Zarówno płodozmian, jak i uprawa roli są zalecane w celu obniżenia stopnia zanieczyszczenia roślin grzybami pleśniowymi rodzaju Fusarium spp. (Weber 2007; Blandino i wsp. 2009; Mesterházy i wsp. 2012). W ujęciu syntetycznym za okres 4 lat badań nie wykazano istotnego wpływu jednorazowego przerwania 10-letniej uprawy kukurydzy w monokulturze pełną dawką obornika na wielkość porażenia roślin kukurydzy w kolejnych latach uprawy. Wyłącznie zróżnicowane nawożenie mineralne NPK w istotny sposób kształtowało wartość tej cechy (tab. 1). Przedsiewne stosowanie NPK, w istotny sposób zmniejszyło procent roślin porażonych przez grzyby rodzaju Fusarium spp., w porównaniu do nawożenia PK przed siewem kukurydzy i N w fazie 5-6 liści (BBCH 15-16). W badaniach własnych wykazano również, że porażenie roślin kukurydzy przez grzyby rodzaju Fusarium spp. było wprost proporcjonalne do sumy opadów atmosferycznych (współczynnik zmienności 0,806), natomiast wpływ temperatury nie był statystycznie istotny. Duże znaczenie dla zdrowotności kukurydzy ma termin zbioru, gdyż kukurydza pozostająca zbyt długo na polu jest silnie 
Tabela 1. Porażenie kukurydzy przez grzyby rodzaju Fusarium spp.

Table 1. Infection of maize by Fusarium spp.

\begin{tabular}{|c|c|c|c|c|c|c|c|c|c|c|c|}
\hline \multirow{3}{*}{\multicolumn{2}{|c|}{$\begin{array}{c}\text { Wyszczególnienie } \\
\text { Specification }\end{array}$}} & \multicolumn{8}{|c|}{$\begin{array}{c}\text { Lata kalendarzowe / Lata po zastosowaniu obornika } \\
\text { Calendar years / Years after manure application }\end{array}$} & \multirow{2}{*}{\multicolumn{2}{|c|}{$\begin{array}{l}\text { Średnio } \\
\text { Mean }\end{array}$}} \\
\hline & & \multicolumn{2}{|c|}{$2008 / 0$} & \multicolumn{2}{|c|}{$2009 / 1$} & \multicolumn{2}{|c|}{$2010 / 2$} & \multicolumn{2}{|c|}{$2011 / 3$} & & \\
\hline & & {$[\%]$} & $\begin{array}{c}\circ \\
\text { Blissa } \\
\end{array}$ & {$[\%]$} & $\begin{array}{c}\circ \\
\text { Blissa } \\
\end{array}$ & {$[\%]$} & $\begin{array}{c}\circ \\
\text { Blissa } \\
\end{array}$ & {$[\%]$} & $\begin{array}{c}\circ \\
\text { Blissa } \\
\end{array}$ & {$[\%]$} & $\begin{array}{c}\circ \\
\text { Blissa } \\
\end{array}$ \\
\hline \multirow{2}{*}{$\begin{array}{l}\text { Stosowanie } \\
\text { obornika } \\
\text { Application of } \\
\text { manure }\end{array}$} & $\begin{array}{l}\text { bez obornika } \\
\text { without manure }\end{array}$ & 0,36 & 2,38 & 15,15 & 21,67 & 15,70 & 21,98 & 18,13 & 23,81 & 12,34 & 17,46 \\
\hline & $\begin{array}{l}\text { z obornikiem }^{*} \\
\text { with manure }\end{array}$ & 1,13 & 4,15 & 15,85 & 21,61 & 16,21 & 21,83 & 18,85 & 23,74 & 13,01 & 17,83 \\
\hline \multicolumn{2}{|c|}{$\operatorname{NIR}(0,05)-\operatorname{LSD}(0.05)$} & - & r.n. & - & r.n. & - & r.n. & - & r.n. & - & r.n. \\
\hline \multirow{2}{*}{$\begin{array}{l}\text { Nawożenie } \\
\text { NPK } \\
\text { Fertilization } \\
\text { NPK }\end{array}$} & $\begin{array}{l}\text { NPK przed } \\
\text { siewem } \\
\text { NPK before } \\
\text { sowing }\end{array}$ & 0,25 & 1,45 & 12,25 & 19,44 & 12,51 & 19,62 & 14,57 & 21,25 & 9,89 & 15,44 \\
\hline & $\begin{array}{l}\text { PK przed } \\
\text { siewem, } \\
\text { N pogłównie } \\
\text { PK before } \\
\text { sowing, } \\
\text { N top-dressing } \\
\end{array}$ & 1,24 & 5,08 & 18,75 & 23,85 & 19,40 & 24,19 & 22,41 & 26,30 & 15,45 & 19,85 \\
\hline \multicolumn{2}{|c|}{$\operatorname{NIR}(0,05)-\operatorname{LSD}(0.05)$} & - & r.n. & - & r.n. & - & r.n. & - & r.n. & - & 2,682 \\
\hline \multicolumn{2}{|l|}{ Średnio-Mean } & 0,75 & 3,26 & 15,50 & 21,64 & 15,95 & 21,91 & 18,49 & 23,77 & 12,67 & 17,65 \\
\hline
\end{tabular}

r.n. - różnice nieistotne - not significant differences

*obornik zastosowano jednorazowo w roku 2007 - manure applied only once in 2007

Tabela 2. Uszkodzenia kukurydzy powodowane przez $O$. nubilalis

Table 2. Damages of maize caused by $O$. nubilalis

\begin{tabular}{|c|c|c|c|c|c|c|c|c|c|c|c|}
\hline \multirow{3}{*}{\multicolumn{2}{|c|}{$\begin{array}{l}\text { Wyszczególnienie } \\
\text { Specification }\end{array}$}} & \multicolumn{8}{|c|}{$\begin{array}{l}\text { Lata kalendarzowe / Lata po zastosowaniu obornika } \\
\text { Calendar years / Years after manure application }\end{array}$} & \multirow{2}{*}{\multicolumn{2}{|c|}{$\begin{array}{l}\text { Średnio } \\
\text { Mean }\end{array}$}} \\
\hline & & \multicolumn{2}{|c|}{$2008 / 0$} & \multicolumn{2}{|c|}{$2009 / 1$} & \multicolumn{2}{|c|}{$2010 / 2$} & \multicolumn{2}{|c|}{$2011 / 3$} & & \\
\hline & & {$[\%]$} & $\begin{array}{c}\circ \\
\text { Blissa }\end{array}$ & {$[\%]$} & $\begin{array}{c}\circ \\
\text { Blissa }\end{array}$ & {$[\%]$} & $\begin{array}{c}\circ \\
\text { Blissa }\end{array}$ & {$[\%]$} & $\begin{array}{c}\circ \\
\text { Blissa }\end{array}$ & {$[\%]$} & $\begin{array}{c}\circ \\
\text { Blissa }\end{array}$ \\
\hline $\begin{array}{l}\text { Stosowanie } \\
\text { obornika }\end{array}$ & $\begin{array}{l}\text { bez obornika } \\
\text { without manure }\end{array}$ & 1,88 & 7,80 & 3,45 & 10,27 & 7,18 & 15,35 & 10,32 & 18,57 & 5,71 & 13,00 \\
\hline $\begin{array}{l}\text { Application of } \\
\text { manure }\end{array}$ & $\begin{array}{l}\text { z obornikiem } \\
\text { with manure }\end{array}$ & 0,68 & 4,68 & 3,21 & 9,78 & 9,02 & 16,94 & 9,56 & 17,93 & 5,62 & 12,33 \\
\hline \multicolumn{2}{|c|}{$\operatorname{NIR}(0,05)-\operatorname{LSD}(0.05)$} & - & r.n. & - & r.n. & - & r.n. & - & r.n. & - & r.n. \\
\hline \multirow{2}{*}{$\begin{array}{l}\text { Nawożenie } \\
\text { NPK } \\
\text { Fertilization } \\
\text { NPK }\end{array}$} & $\begin{array}{l}\text { NPK przed } \\
\text { siewem } \\
\text { NPK before } \\
\text { sowing }\end{array}$ & 1,35 & 6,33 & 2,18 & 8,31 & 7,94 & 16,06 & 8,74 & 17,06 & 5,05 & 11,94 \\
\hline & \begin{tabular}{|l|} 
PK przed \\
siewem, N \\
pogłównie \\
PK before \\
sowing, \\
N top-dressing
\end{tabular} & 1,20 & 6,15 & 4,49 & 11,74 & 8,25 & 16,23 & 11,14 & 19,44 & 6,27 & 13,39 \\
\hline \multicolumn{2}{|c|}{$\operatorname{NIR}(0,05)-\operatorname{LSD}(0.05)$} & - & r.n. & - & r.n. & - & r.n. & - & r.n. & - & 1,079 \\
\hline \multicolumn{2}{|l|}{ Średnio - Mean } & 1,28 & 6,24 & 3,33 & 10,02 & 8,10 & 16,14 & 9,94 & 18,25 & 5,66 & 12,66 \\
\hline
\end{tabular}

r.n. - różnice nieistotne - not significant differences

*obornik zastosowano jednorazowo w roku 2007 - manure applied only once in 2007 
narażona na wyleganie roślin, porażenie przez Fusarium spp. i inne patogeny wywołujące zgorzel podstawy łodyg oraz fuzariozę kolb. Pogłówne stosowanie pełnej dawki azotu w badaniach własnych było prawdopodobnie czynnikiem opóźniającym dojrzewanie kukurydzy, co skutkowało zwiększeniem porażenia roślin przez grzyby rodzaju Fusarium spp. Blandino i wsp. (2008a) podają, że ilość i rodzaj zastosowanego azotu kształtuje gromadzenie mikotoksyn w ziarnie kukurydzy. Tylko zrównoważone nawożenie może spowodować niższą ich kumulację w ziarnie. Opóźnienie terminu zbioru, zwłaszcza jeśli jesień jest deszczowa powoduje wzrost ryzyka porażenia kolb przez Fusarium spp. W badaniach włoskich wykazano (Blandino i wsp. 2008b), że wczesny siew kukurydzy oraz wybór do uprawy mieszańców wcześnie dojrzewających zmniejsza ryzyko porażenia roślin grzybami pleśniowymi rodzaju Fusarium spp. Toksycznym następstwem ich rozwoju jest obecność produktów wtórnego metabolizmu, takich jak fumonizyny (Dilkin i wsp. 2010).

W integrowanej ochronie kukurydzy przed szkodnikami zdaniem Beresia i Pruszyńskiego (2008) ważne jest stosowanie płodozmianu. System uprawy kukurydzy w monokulturze przyczynia się do wzrostu szkodliwości najgroźniejszego szkodnika, jakim jest omacnica prosowianka (Bereś 2007). W badaniach własnych na wielkość uszkodzeń kukurydzy przez gąsienice omacnicy prosowianki oprócz długości uprawy w monokulturze i zmiennych w latach warunków pogodowych w czasie wegetacji wpływały również czynniki doświadczenia (tab. 2). Istotnie najmniejszy procent roślin $\mathrm{z}$ objawami żerowania gąsienic uzyskano $\mathrm{w}$ roku 2008 (1,28\%), natomiast największy w roku 2011 (9,94\%). Największy procent roślin kukurydzy uszkodzonych przez gąsienice omacnicy prosowianki odnotowano w ostatnim roku badań
(2011), który charakteryzował się największą średnią dobową temperaturą powietrza $\left(15,9^{\circ} \mathrm{C}\right)$, natomiast suma opadów atmosferycznych była na poziomie 424,2 $\mathrm{mm}$ (rys. 1). Również Wałkowski i Bubniewicz (2004) wykazali, że ekspansja omacnicy prosowianki na terenie Wielkopolski
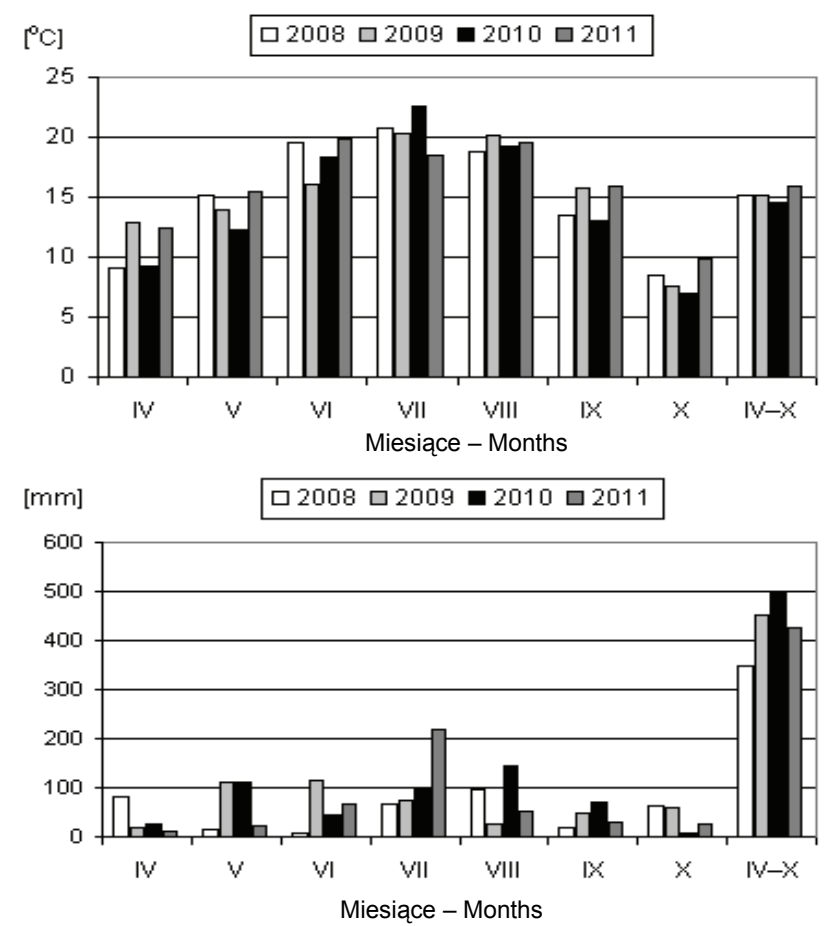

Rys. 1. Średnia temperatura powietrza oraz suma opadów atmosferycznych w sezonach wegetacyjnych kukurydzy

Fig. 1. Mean air temperature and amount of precipitation in maize vegetation seasons
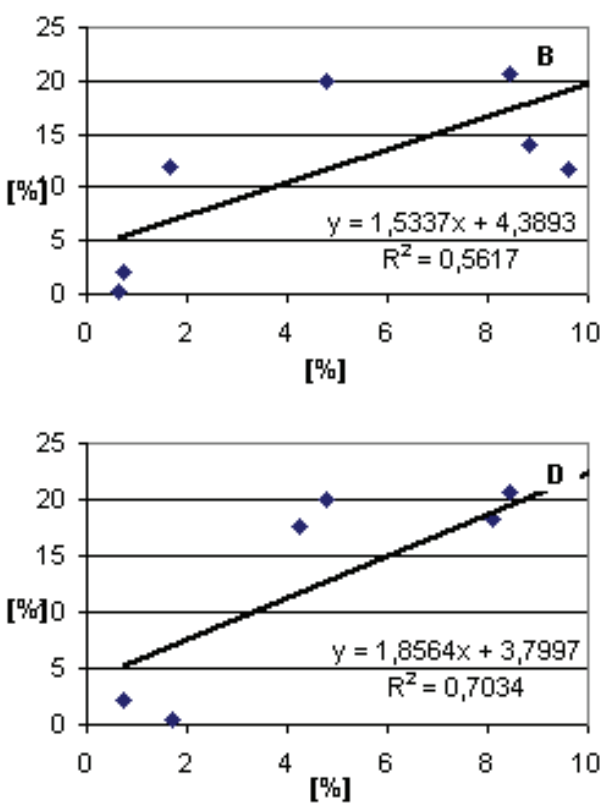

Rys. 2. Zależność pomiędzy występowaniem omacnicy prosowianki a porażeniem roślin przez choroby fuzaryjne: A - bez stosowania obornika, B - z obornikiem, C - NPK przed siewem, D - PK przed siewem N w fazie 5-6 liści (2008-2011)

Fig. 2. Relationship between prevalence of European corn borer and plant infestation with fusarium diseases: A - without application of manure, B - with manure, C - NPK before sowing, D - PK before N sowing in the 5-6 leaf stage (2008-2011) 
następuje w wyniku ocieplenia klimatu i deficytu opadów. W ujęciu syntetycznym wyłącznie zróżnicowane nawożenie mineralne $\mathrm{w}$ istotny sposób kształtowało wielkość żerowania gąsienic (tab. 2). Stosowanie PK przed siewem i N w fazie 5-6 liści (BBCH 15-16) w istotny sposób zwiększało ilość uszkodzeń kukurydzy powodowanych przez $O$. nubilalis, w porównaniu do przedsiewnej aplikacji NPK. W badaniach własnych wykazano również ścisłą zależność pomiędzy występowaniem omacnicy prosowianki a porażeniem roślin kukurydzy przez choroby fuzaryjne (rys. 2). Zależność ta została opisana równaniem $1^{\circ}$. Wraz ze wzrostem uszkodzeń roślin kukurydzy przez tego szkodnika, porażenie przez grzyby rodzaju Fusarium ssp. ulegało również zwiększeniu. Uzyskany wynik w badaniach własnych jest potwierdzeniem wcześniejszych doniesień literaturowych (Lisowicz i Tekiela 2004) mówiących o tym, że porażeniu roślin przez zgniliznę korzeni i zgorzel podstawy łodyg sprzyja żerowanie mszyc, przylżeńców, rolnic, omacnicy prosowianki i innych szkodników. Również Ajanga i Hillocks (2000) podają, że rośliny uszkodzone przez omacnicę proso- wiankę są intensywniej porażane przez patogeny grzybowe.

\section{Wnioski / Conclusions}

1. Przerwanie jednorazowo pełną dawką obornika 10-letniej uprawy kukurydzy w monokulturze nie wpływało w kolejnych latach na wielkość porażenia przez grzyby rodzaju Fusarium spp. oraz uszkodzenia powodowane przez $O$. nubilalis.

2. Stosowanie pogłówne azotu $\mathrm{w}$ fazie 5-6 liści $(\mathrm{BBCH}$ 15-16) zwiększało podatność roślin kukurydzy na porażenie przez grzyby rodzaju Fusarium spp. oraz na uszkodzenia powodowane przez $O$. nubilalis .

3. Porażenie roślin kukurydzy przez grzyby rodzaju Fusarium spp. oraz uszkodzenia powodowane przez O. nubilalis zwiększały się w kolejnych latach uprawy kukurydzy w monokulturze.

4. Wykazano wysoki, dodatni współczynnik korelacji pomiędzy występowaniem omacnicy prosowianki a porażeniem roślin kukurydzy przez choroby fuzaryjne.

\section{Literatura / References}

Ajanga S., Hillocks R.J. 2000. Maize cob rot in Kenya and its association with stalk borer damage. Crop Prot. 19: $297-300$.

Bereś P.K. 2007. Szkodliwość omacnicy prosowianki (Ostrinia nubilalis Hbn.) dla kukurydzy uprawianej w zmianowaniu i monokulturze. [Harmfulness of European corn borer (Ostrinia nubilalis Hbn.) to maize grown in crop rotation and in monoculture]. Prog. Plant Prot./Post. Ochr. Roślin 47 (1): 184-187.

Bereś P.K., Pruszyński G. 2008. Ochrona kukurydzy przed szkodnikami w produkcji integrowanej. Acta Sci. Pol., Agricultura 7 (4): $19-32$.

Blandino M., Reyneri A., Vanara F., Pascale M., Haidukowski M., Saporiti M. 2008a. Effect of sowing date and insecticide application against European corn borer (Lepidoptera: Crambidae) on fumonisin contamination in maize kernels. Crop Prot. 27: 1432-1436.

Blandino M., Reyneri A., Vanara F. 2008b. Effect of plant density on toxigenic fungal infection and mycotoxin contamination of maize kernels. Field Crop Res. 106: 234-241.

Blandino M., Reyneri A., Vanara F., Tamietti G., Pietri A. 2009. Influence of agricultural practises on Fusarium infection, fumonisin and deoxynivalenol contamination of maize kernels. World Mycotoxin J. 2 (4): 409-418.

Dilkin P., Direito G., Simas M.M.S., Mallmann C.A., Correa B. 2010. Toxicokinetics and toxicological effects of single oral dose of fumonisin B1 containing Fusarium verticillioides culture material in weaned piglets. Chemico-Biological Interactions 185: 157-162.

Dubas A., Drzymała S., Mocek A., Owczarzak W., Szulc P. 2012. Wpływ uproszczeń w uprawie roli w wieloletniej monokulturze kukurydzy (Zea mays L.) na właściwości gleby oraz przebieg wegetacji i plonowanie. Wydawnictwo UP Poznań: 7-74.

Howard R.J. 1996. Cultural control of plant diseases: a historical perspective. Can. J. Plant Pathol. 18: 145-150.

Kotwica K. 2004. Skutki różnego zagospodarowania słomy pszennej w trakcie uprawy pożniwnej pod jęczmień jary, w warunkach monokultury zbożowej. Fragm. Agron. 21, 3 (83): 95-106.

Krauss A. 2001. Potassium and biotic stress. p. 281-293. In: Proc. 1st Fauba-Fertilizar-IPI Workshop on Potassium in Argentina's Agricultural System. Buenos Aires, 20-22 November 2001, 311 pp.

Kuś J., Siuta A., Mróż A., Kamińska M. 1993. Możliwość kompensacji ujemnego wpływu stanowiska na plonowanie jęczmienia jarego. Pam. Puł. 103: 133-143.

Lisowicz F., Tekiela A. 2004. Szkodniki i choroby kukurydzy oraz ich zwalczanie. s. 52-64. W: „Technologia produkcji kukurydzy” (A. Dubas, red.). Wieś Jutra, Warszawa, 133 ss

Menzel L., Dubas A. 2003. Reakcja kukurydzy uprawianej w monokulturze na uproszczenia w uprawie roli. Pam. Puł. 133: 123-134.

Mesterházy Á., Lemmens M., Reid L.M. 2012. Breeding for resistance to ear rots caused by Fusarium ssp. in maize - a review. Plant Breeding 131: 1-19.

Tabaglio V., Gavazzi C. 2009. Monoculture maize (Zea mays L.) cropped under conventional tillage, no-tillage and N fertilization: (I) Three year yield performances. Ital. J. Agron. 4-3: 61-67.

Wałkowski W., Bubniewicz P. 2004. Omacnica prosowianka (Ostrinia nubilalis Hbn.) - ekspansywny szkodnik kukurydzy w Wielkopolsce. [European corn borer (Ostrinia nubilalis Hbn.) - an expansive pest of maize in Wielkopolska region]. Prog. Plant Prot./Post. Ochr. Roślin 44 (2): 1187-1190.

Weber R. 2007. Zagrożenie i sposoby ograniczania chorób fuzaryjnych pszenicy. Post. Nauk Rol. 59 (2): 19-31.

Wesołowski M., Woźniak A. 1998. Plonowanie i zachwaszczenie kukurydzy uprawianej w zmianowaniu dowolnym i monokulturze na glebie wytworzonej z piasku. Fragm. Agron. 3 (59): 70-79. 